This item was submitted to Loughborough's Research Repository by the author.

Items in Figshare are protected by copyright, with all rights reserved, unless otherwise indicated.

\title{
Acting local, thinking global: Globalizing resilience through 100 resilient cities
}

PLEASE CITE THE PUBLISHED VERSION

https://doi.org/10.1177/2336825X20906315

PUBLISHER

Sage

VERSION

AM (Accepted Manuscript)

\section{PUBLISHER STATEMENT}

This paper was accepted for publication in the journal New Perspectives and the definitive published version is available at https://doi.org/10.1177/2336825X20906315. Users who receive access to an article through a repository are reminded that the article is protected by copyright and reuse is restricted to non-commercial and no derivative uses. Users may also download and save a local copy of an article accessed in an institutional repository for the user's personal reference. For permission to reuse an article, please follow our Process for Requesting Permission.

\section{LICENCE}

CC BY-NC-ND 4.0

\section{REPOSITORY RECORD}

Zebrowski, Chris. 2020. "Acting Local, Thinking Global: Globalizing Resilience Through 100 Resilient Cities". Loughborough University. https://hdl.handle.net/2134/11323352.v1. 


\title{
Acting Local, Thinking Global: Globalizing Resilience through 100 Resilient Cities [Title]
}

\author{
Chris Zebrowski \\ Loughborough University
}

\begin{abstract}
This article investigates the globalization of resilience by examining a particular and prominent vehicle for the dissemination of resilience-ideas: the Rockefeller Foundation's 100 Resilient Cities (100RC) initiative. As a philanthropic initiative organized through a network of international cities, 100RC demonstrates how the spread of resilience-thinking has been facilitated by exploiting changes in the structures and processes of global governance afforded by neoliberal globalization. The analysis focuses on explicating 100RC's animating logic of governance, which is committed to the cultivation of network connectivity. Rather than directly fostering resilience, connectivity is established as a condition under which resilience solutions can be immanently surfaced from the interactions of a diverse selection of stakeholders brought together through these networks. The article situates this governmental logic within broader changes associated with neoliberal globalization, namely: the emergence of multi-scalar governance networks, the rise of philanthrocapitalism and the inception of platform capitalism. The conclusion discusses the implications of this analysis for further study of the relation between connectivity, danger, knowledge and value contained within resilience discourses.
\end{abstract}

\section{Keywords: Urban Resilience, Neoliberalism, Globalization, 100RC, Connectivity}

\section{Introduction: Globalizing Resilience [Subtitle Level 1]}

The 100 Resilient Cities initiative is an exclusive network of 100 cities from around the world committed to enhancing 'urban resilience'. Launched in 2013 , the network has steadily expanded from 32 to 100 cities (100 Resilient Cities, nd, e), with the latest selection process receiving over 1000 applications from prospective cities. The 100RC initiative signals the Rockefeller Foundation's commitment to the idea of resilience as a core concept driving its philanthropic activities.

As a philanthropic initiative organized through a network of international cities, 100RC demonstrates how the spread of resilience-thinking has been dependent on exploiting changes in the structures and processes of global governance afforded by neoliberal 
globalization. To date, the majority of research into the politics of resilience has been conducted at familiar scales of analysis: international (Joseph, 2016; Reid, 2012), national (Joseph, 2013; Lentzos \& Rose, 2009) and municipal (Collier, Cox, \& Grove, 2016; Rademaker et al., 2018; Zebrowski \& Sage, 2016). By concentrating on these reified scales of analysis, such studies tend to overlook the ways in which resilience ideas are increasingly being promoted through novel political channels that have been opened up by neoliberal globalization. The 100RC initiative shows us how resilience ideas are being promoted in a manner that eludes, and even subverts, the traditional scales and modes of global governance. 100RC is an international initiative, but one which targets municipalities directly as the key governmental bodies responsible for overcoming urban resilience challenges. 100RC is organized and financed by the Rockefeller Foundation. As a philanthropic body, the Rockefeller Foundation has a limited governmental role-primarily directed towards fostering connections between member cities and associated partners from the private and charitable sectors. Resilience solutions in this way are not imposed in a top-down manner, but (it is hoped) immanently realized from the interactions of internationally based groups affiliated with the 100RC network. In both its contortions of governmental scale and style of indirect governance $100 R C$ is clearly advancing an innovative model of governance in its efforts to promote resilience ideas globally.

In this article I aim to elucidate the logic of governance enacted within the 100RC initiative. In the following analysis, particular attention is paid to how connectivity is understood and governed within the remit of the 100RC initiative. I begin by elucidating the governmental imaginary guiding the 100RC initiative by critically reviewing the book The Resilience Dividend (Rodin, 2014). Authored by then President of the Rockefeller Foundation Judith Rodin (2005-2017), it makes a clear statement on how the Rockefeller Foundation understands the nature of urban challenges and how resilience may be applied to address these problems. In particular, this critical review will establish how connectivity is presented within this imaginary as a source of new dangers, knowledge and value. This insight will then be used as a framework to guide an empirical analysis of the 100RC initiative. The analysis of open-source materials located on the 100RC website investigates how networked modes of connectivity are utilized as a means of exercising a form of indirect governance; producing new knowledge with regard to urban problems and resilience solutions; and creating value via the realization of a 'resilience dividend'. The final section of the article then situates this 
governmental logic within broader developments associated with neoliberal globalization. The aim here is to show how $100 R C$ mirrors, and resonates with, three recent developments in the evolution of global governance: the proliferation of multi-scalar governance networks, the rise of philanthrocapitalism and the advent of platform capitalism. I conclude with a brief discussion of implications of this analysis for further study of the relation between connectivity, danger, knowledge and value embedded within resilience discourses more broadly.

\section{Connectivity and Resilience [Subtitle Level 1]}

Judith Rodin, the president of the Rockefeller Foundation from 2005-2017, begins her book The Resilience Dividend: Being Strong in a World Where Things Go Wrong (2014) by identifying three distinctly contemporary challenges facing global life: urbanization, climate change and globalization. Urbanization refers to the growing size and density of cities, which "make them newly vulnerable to disruption, crisis, and disaster in many ways" (Rodin, 2014: 4). The second, climate change, can be witnessed in the increasing frequency and severity of extreme weather events (Rodin, 2014: 4-5). Thirdly, globalization, "has accelerated the pace of change, introduced new and unaccustomed risks, added complexity to our systems, and increased the amount of volatility we face-particularly economic volatility" (Rodin, 2014: 5). Rodin argues that the unprecedented danger associated with these processes arises from their interconnectedness:

These three factors are intertwined and affect one another in a social-ecologicaleconomic nexus. Because everything is interconnected-a massive system of systemsa single disruption often triggers another, which exacerbates the effects of the first, so that the original shock becomes a cascade of crises (Rodin, 2014: 5).

"The good news", Rodin assures us, "is that resilience building is a concept that can be learned and a practice that can developed.... When we do that, we can create and lead lives less shadowed by threat, develop communities and organizations that are more productive and innovative, and strengthen societies such that they are brimming with greater opportunity and prosperity" (Rodin, 2014: 6). This payoff from investing in resilience is what Rodin describes as the resilience dividend. "The resilience dividend", Rodin says, "not only enables people and communities to rebound faster from disasters or deal with stresses; 
it spurs economic development, job creation, environmental sustainability, and social cohesion" (Rodin, 2014: 295-296).

Resilience here is presented as a panacea for a spectacular variety of contemporary social and environmental ills. In this regard, Rodin's book is far from exceptional. In fact, one could view it as a fairly typical example of a torrent of literature (Gilpin \& Murphy, 2008; Hadfield \& Hassob, 2009; Oaklander, 2015; Wagner \& Disparte, 2016) championing resilience as a security solution to the growing uncertainty and dangers of the contemporary world. Rodin states this explicitly: "I believe that building resilience is of paramount importance today, especially as we see that the problems of the world are growing increasingly threatening" (2014: 280). In an environment where threats are increasingly difficult to predict and prevent, resilience promises that when events happen one has the capacity to "bounce back from a crisis, learn from it, and achieve revitalization" (Rodin, 2014: 3). While one could (and perhaps should) challenge the assumption that we are living in an era of unprecedented danger, ${ }^{1}$ it is critical to identify that the rise of resilience has been dependent on a widespread intuition of danger. So what is it that makes danger so exceptional today?

Rodin draws on an ontology of complexity to understand the particular danger of contemporary threats (with no mention of or engagement with a now sizable literature questioning the ontological and epistemological assumptions of complexity theory as it has been applied to resilience-thinking (Chandler, 2014; Walker \& Cooper, 2011; Zebrowski, 2013)). For Rodin the particular dangerousness of contemporary threats is associated with the 'interconnectedness' of the 'systems of systems' comprising and underpinning contemporary life (2014: 5). Disruptions within one system can quickly cascade to affiliated systems via these connections. Discrete problems become amplified as they cascade across systems, spreading spatially and increasing in complexity and severity.

A weather disturbance, for example, can cause infrastructural damage that leads to a public health problem that, in turn, disturbs livelihoods and creates widespread economic turmoil, which can lead to a further degrading of basic services, additional health problems, and even political conflict or civil unrest (Rodin, 2014: 5).

The particular dangers associated with the three era-defining global challenges Rodin identifies-urbanization, climate change and globalization-stem from the

\footnotetext{
${ }^{1}$ One could just as easily make the case that we are living in the safest times in world history.
} 
interconnectedness of contemporary life and the interconnectedness these challenges themselves accelerate and intensify. Dangers spill across systems of systems-but they likewise emerge at the intersection of disciplinary silos through which we have organized our knowledge of the world. Responding to such dangers calls for a new way of understanding the world; one that integrates the disciplinary silos ordering the sciences of life into a "social-ecological-economic nexus" (2014: 5).

It becomes clear that if the interconnectedness of contemporary life is the source of our particular vulnerability, it also holds the promise of enhanced security. Within Rodin's book, the association of connectivity and resilience is established through a series of examples and vignettes. For example, an innovative and integrated transportation system in Medellin fostered resilience by connecting poor communities with economic opportunities and reduced crime rates dramatically (Rodin, 2014: 9-13). The comprehensive flood protection program introduced in Tulsa, Oklahoma was achieved by integrating groups into a "cohesive, connected community" that "produced diversity of opinions and options for improvements" (Rodin, 2014: 100). Online platforms, including Airbnb, yerdle and Taskrabbit, are identified as having a potentially 'transformational' role in disaster relief: "with these online networks and communities already in place, the transition from everyday business to postdisruption operation could be seamless, facilitating a more rapid response" (Rodin, 2014: 274).

Across these examples, Rodin establishes a relation between connectivity and resilience in which the former realizes the latter by harnessing diversity: integrating different groups, ideas, and products into the disaster relief assemblage. Here, Rodin's book echoes the prioritization given to connectivity across a wide range of practitioner and academic discourses on resilience, from the concept of panarchy (the cross-system connections in space and time) amongst systems ecologists (Wilson et al., 2013) to network connectivity as dealt with by network scientists (Lewis, 2009: 375), or social capital as examined by community resilience organizers (Aldrich \& Meyer, 2015). While we should be wary of conflating quite different enactments of both connectivity and resilience here (Anderson, 2015), it is safe to say that connectivity is recognized as a fundamental driver of resilience across a wide selection of disciplines developing the concept of resilience. Connectedness is valued as a means of harnessing diversity within the networked forms required not only to 'surface' (100 Resilient Cities, nd, c) solutions to the complex, multi-disciplinary problems of today, but also to capitalize on emerging opportunities. 
Drawing on the language of finance, Rodin describes the value which can be captured by realizing resilience as the 'resilience dividend'.

The resilience dividend not only enables people and communities to rebound faster from disasters or deal with stresses; it spurs economic development, job creation, environmental sustainability, and social cohesion. It brings benefit to people, organizations, and communities when things are going right as well as when they go wrong (Rodin, 2014: 295-296).

The resilience dividend promises benefits to multiple stakeholders in the present and future. Like the concept of antifragility (Taleb, 2012), the resilience dividend suggests that truly fulfilling the promise of resilience goes beyond the simple capacity to bounce-back from crises, and includes the capacity to profit, grow and positively transform oneself through exposure to crises. As with logics of disaster capitalism, one can invite, and even manufacture, crises as a way of compelling further innovation and growth (Klein, 2007). The payoff of investing in resilience is not simply the savings wrought by not spending on expensive recovery operations, but ensuring that one is placed to gain from an increasingly insecure and turbulent world. The resilience dividend is a central part of the 100RC promise, and has led the Rockefeller Foundation to commission research attempting to develop metrics for its measurement from both the Overseas Development Institute and the RAND Corporation (Leitner et al., 2018: 1282).

The framing of resilience as a form of capital is hardly novel. C.S. Holling explicitly discussed resilience as a kind of 'ecosystem capital' underpinning the capacity not just to bounce-back from crises, but also to realize new potentials (Holling, 2001: 394-395). 'Social capital' -an abstract measure of the degree of connectivity and richness of the social networks comprising a community-is likewise regularly championed as a means of achieving community resilience (Mulligan \& Rogers, 2017; Zebrowski \& Sage, 2016). In business and management literatures, 'human capital' has been identified as the key to maximizing individual and organizational resilience within increasingly dynamic work environments (Luthans, Luthans, \& Luthans, 2004; Luthans, Vogelgesang, \& Lester, 2006; Youssef \& Luthans, 2007). For critics of resilience, the absorption of the language of capital and finance into resilience discourses is indicative of deeper discursive affinities between resilience and neoliberalism. Discourses of resilience have been critiqued as promoting programmes of neoliberal responsibilization in which individuals and groups are compelled to develop the entrepreneurial capacities required to manage their own individual risks (Chandler, 2014; 
Evans \& Reid, 2014; Neocleous, 2013; Walker \& Cooper, 2011; Zebrowski, 2016). Despite the importance of such critiques in highlighting the mutual imbrication of resilience and neoliberalism as governmental projects, critiques of resilience have given less attention to the particular logic of capital that is being reiterated across these varied discourses and applications of resilience.

This is a question I will return to closer to the end of this analysis. At this point, what is critical is understanding how the problem of connectivity is linked to the generation of danger, knowledge and value within the urban resilience discourse advanced by Rodin. Crucially, connectivity is regarded as both the cause of and solution to the problem of the radical contingency of contemporary threat. The interconnectivity of vital systems of systems may be the source of acute vulnerability, but connectivity is also the condition for the realization of enhanced security. Knowledge, understood as solutions to complex problems, is tied to the ability to transcend outdated disciplinary silos to understand complex problems from a multidisciplinary perspective and 'surface' integrated, joined-up solutions. Value, in the form of the 'resilience dividend', is produced through investments that forge rich new connections between people, places, products and services. Danger, knowledge and value are each cast as emergent functions of the complex interactions of discrete systems.

This approach is curious. On the one hand, it relies on the assumption that solutions to some of the world's most complex problems, in a sense, already exist, albeit in a state of dormancy. The truth is out there; it just needs to be joined-up, actualized, or 'surfaced'. So, the search for global solutions becomes a project of breaking down silos; putting into relation fragmentary perspectives, partial solutions and half-truths; and connecting individuals, groups, and ideas. Solutions exist, but they need to be excavated from the interstices; dusted off and put to work. On the other hand, we should be aware that such an understanding of contemporary security problems facilitates the introduction of novel, technocratic solutions to what many would argue are ultimately political problems. In the analysis which follows, we will see how the 100RC initiative has been designed to operationalize this relation between connectivity, danger, knowledge and value and translate it into a programme of resilience governance.

\section{The 100 Resilient Cities (100RC) Initiative [Subtitle Level 1]}


The 100RC network was established and funded by the Rockefeller Foundation: one of America's most prominent and historical philanthropic organizations. Since 1906, the Rockefeller Foundation has sought to mobilize the substantial profits made by their oil and gas business to further their stated mission of "promoting the well-being of humanity throughout the world" (Rockefeller Foundation, nd). The Rockefeller Foundation's interest in resilience came to the fore in $\mathbf{2 0 0 7}$ with the multi-million dollar contribution to the 'Building Climate Change Resilience Initiative'. This programme promised to "develop practices, processes, and networks that will be crucial to building climate change resilience, and will lay the groundwork for increased awareness and action toward building the resilience of poor and vulnerable communities worldwide" (Rockefeller Foundation, 2009: 7). Since that time, Rockefeller's interest in resilience has expanded both geographically, from the world's poorest regions to cities located in many of the world's most affluent countries, and thematically, from a focus on climate change to a broader spectrum of threats afflicting urban centres.

The 100 Resilient Cities initiative began in 2013 and has become, in many ways, the Rockefeller Foundation's flagship policy. The 100RC network aims to enhance 'urban resilience", defined as the "capacity of individuals, communities, institutions, businesses, and systems within a city to survive, adapt, and grow no matter what kinds of chronic stresses and acute shocks they experience" (100 Resilient Cities, nd, g). Acute shocks refer to sudden events such as earthquakes, floods, disease outbreaks, and terrorist attacks. Chronic stresses, by contrast, refer to persistent or cyclical problems that undermine a city's capacity to bounce back from acute shocks, such as high unemployment, inefficient public transportation systems, endemic violence, and chronic food and water shortages. In the analysis that follows we will look to elucidate the logic of governance underpinning the 100RC initiative. Drawing on the critical review undertaken above, the analysis will focus on how resilience is being advanced as a solution to urban problems within which connectivity is posed as a source of danger, knowledge and value. This will be achieved by examining the design of 100RC with respect to three features: its indirect mode of governance; its method for identifying resilience challenges; and its promise to deliver 'resilience dividends'. 


\section{Cultivating Connectivity [Subtitle Level 2]}

100RC, according to the Rockefeller Foundation, is "dedicated to helping cities around the world become more resilient to the physical, social and economic challenges that are a growing part of the 21st century" (100 Resilient Cities, nd, a). The manner in which urban resilience is to be achieved is decidedly bottom-up. Urban resilience problems are to be immanently identified and addressed through the interactions of member cities and platform partners, including private businesses, public sector organizations and charitable bodies. On the face of it, the Rockefeller Foundation's role is strictly limited: it oversees regular competitions for cities seeking inclusion in the 100 Resilient Cities network and provides financial support to its members. However, this would be to overlook the significant governmental responsibilities of the Rockefeller Foundation in establishing and cultivating this network. By its exercising of a mode of resilience governance that operates "at a distance" (Miller \& Rose, 1992), the principal role of the Rockefeller Foundation is to foster the connections necessary for urban resilience problems to be identified, innovative resiliencebased solutions to be assembled, and 'resilience dividends' to be realized.

Cities are selected for 100RC through a competition overseen by the Rockefeller Foundation. Prospective cities must undertake a self-evaluation which is assessed by judges appointed by the Foundation on criteria including "innovative mayors, a recent catalyst for change, a history of building partnerships, and an ability to work with a wide range of stakeholders" (100 Resilient Cities, nd, a). Member cities are thus often, to a considerable extent, familiar with the idea of resilience and successful in enacting it through municipal plans and strategies (Goldstein et al., 2015: 229). The competition is important in cultivating an aura of prestige and exclusiveness for the club, which many cities seek for brand management. In the most recent competition 37 cities were selected from over 1,000 applicants.

Cities that are successful in their application to the 100RC network are awarded \$1 million (US) of funding by the Rockefeller Foundation for the appointment of a Chief Resilience Officer (or CRO). A CRO is a top-level advisor to the city's mayor or chief executive who is directly embedded into the governing organization of that city (e.g. a city council or an equivalent body) for the purposes of promoting resilience. CRO's are appointed based on 
their area of expertise and they are located within the structure of the governing organization based on the nature of the resilience challenges identified within the evaluation process (Rogers, 2019: 134). CRO's are expected to use the tools and specialist consultancies recommended by Rockefeller to assess the resilience challenges of the locale and deliver a formal resilience strategy, including an implementation plan, within two years of their appointment (Rogers, 2019: 134). The appointment of the CRO directly into the structures of municipal governance provides them with a level of access and influence above those of individuals operating within traditional civil society. Overall, the funding of this position represents a particularly successful strategy for raising the profile of resilience within municipalities that are often short of funds.

Resilience as a strategic priority is directly inculcated into core governance practices through the CRO. As with the bottom-up approach taken by the Rockefeller Foundation, whose role is to cultivate the $100 R C$ network, the CRO is principally a facilitator of networks at the municipal level. The CRO works to foster connections within and between municipal agencies, facilitate city-to-city collaborations through the 100RC network, and connect members with agencies, consultancies and businesses affiliated with the 100RC Platform Partners. The appointment of the CRO is a response to a perceived problem of 'siloing' afflicting the resilience ambitions of municipal governments. In the words of the Rockefeller Foundation's Managing Director Nancy Kete, local "perspectives [on resilience] were siloed, shaped by experience and expertise in one or another aspect of resilience, disaster risk reduction, infrastructure resilience, climate change, national security or business continuity" (ARUP, 2015: 1). The CRO is thus responsible for facilitating connections between "stakeholders from across silos of government and sectors of society" (100 Resilient Cities, nd, d). As one commentator put it, "The strategic role [of the Chief Resilience Officer] is not one of setting the framework, but rather [of cultivating] the relationships and collaborative working ethics that link resilience thinking into the way governance organisations work" (Rogers, 2019: 136). Over a six-to-nine-month period, the Chief Resilience Officer works to bring people, projects, and priorities together in order to "surface crucial new solutions so that cities can collectively act on their resilience challenges" (100 Resilient Cities, nd, c).

The indirect model of governance enacted by both the Rockefeller Foundation and the CRO is one principally directed towards fostering the forms of connectivity essential for realizing enhanced urban resilience. Neither Rockefeller nor the CROs are resilience experts 
who cascade resilience solutions down through the structures of municipal governance. Instead the 100RC initiative is governed through a form of indirect rule which establishes the networked conditions under which urban resilience problems can be identified and addressed immanently. The following sections focus more specifically on the implications of this logic of governance for the ways in which knowledge and value are understood to be produced through the activities of the 100RC initiative.

\section{Surfacing Knowledge [Subtitle Level 2]}

A member city's resilience strategy is designed in relation to the resilience challenges diagnosed through the City Resilience Index (CRI). The City Resilience Index (CRI) (formerly 'City Resilience Framework' (ARUP, 2015)) was developed by ARUP, a London-based engineering consultancy, with support from the Rockefeller Foundation. The City Resilience Index functions as a self-assessment and best-practice tool "to enable cities to measure and monitor the multiple factors that contribute to their resilience" (ARUP, 2017: 7). The goal, it states, is not to "deliver an overall single score for comparing performance between cities" but to "provide a common basis of measurement and assessment to better facilitate dialogue and knowledge-sharing between cities" (ARUP, 2017: 8). The principal danger to urban centres is identified as the increased scale of urban risks-linked not just to processes of urbanization, but to the ways in which risk itself is "increasingly unpredictable due to the complexity of city systems and the uncertainty associated with many hazards" (ARUP, 2017: 11). The City Resilience Index was developed as a tool to allow urban policy makers to understand the complexity of the city in terms of its interconnected subsystems, identify the shocks and stresses that these different subsystems may face, assess their resilience needs, and apply the indicators set out within the City Resilience Index to measure and monitor resilience.

Seeking to overcome the silos through which resilience and disaster risk reduction were said to have been formerly held (ARUP, 2017: 5), a priority was placed on consulting multiple experts in the development of the City Resilience Index. In their own words,

the purpose of the City Resilience Index is to provide cities with a robust, holistic, and accessible basis for assessment so that they are better placed to make investment decisions and engage in urban planning practices that ensure people living in cities, 
particularly the poor and vulnerable, survive and thrive no matter what shocks and stresses they encounter (ARUP, 2015: 21).

However, the very presence of such a framework raises issues concerning how resilience-related urban problems are identified and understood in the first place. The City Resilience Index clearly operates to render questions of urban resilience technical, so that they may be addressed via commodified 'solutions'. In this sense 100RC appears to embody a "technological/technocratic approach that dominates resilience discourse and practice in an era of neoliberalization" (Tierney, 2015: 1337). As a result, the City Resilience Index simultaneously operates to discourage the framing of such problems as social or political issues requiring more concerted and sustained governmental attention. In this respect, the City Resilience Index appears to restrict the very ways through which problems and solutions pertaining to resilience might be understood and addressed.

\section{Delivering Value [Subtitle Level 2]}

This self-assessment undertaken within the City Resilience Index is used to inform and guide the member city's Resilience Strategy. The City Resilience Strategy is described as "one of the core tools that propels 100 Resilient Cities member cities through the process of building resilience" (100 Resilient Cities, nd, c). It aims to embed collaborative planning practices into all aspects of governance identified as lacking resilience. This is principally achieved by encouraging cities to work with strategic partners listed in the list of 100RC Platform Partners to prepare and execute their strategic plan. By facilitating connections between cities and the Platform Partners, 100RC sees its role as helping cities to "further develop their capacity to design and implement projects that specifically deliver resilience value" (100 Resilient Cities, $\mathrm{nd}, \mathrm{f})$. However this raises questions as to the meaning of value being used here, how it is being generated, and who it is profiting.

Despite the status of the Rockefeller Foundation as a philanthropic body, the Platform Partners clearly signals the importance of the profit motive as an indispensable driver in 100RC's efforts to enhance urban resilience. The Platform Partners comprise a mix of private businesses (e.g. AECOM, ARUP), non-profit organizations (e.g. Save the Children) and international NGOs (e.g. the World Bank, the Overseas Development Institute). However they have been criticized as placing particular emphasis on the role of the private sector generally 
and U.S. and global corporate entities in particular (Tierney, 2015: 1337), including businesses specializing in engineering, information technology, and consulting, such as ARUP, Cisco, Mastercard, Microsoft, and Siemens. Through the Platform Partners, 100 Resilient Cities provides member cities with access to a curated suite of resilience-building tools and services "to help cities around the world become more resilient to the shocks and stresses that are a growing part of the 21 st century" (100 Resilient Cities, nd, f).

The City Resilience Index and Strategy operate in conjunction to open municipal governance to a range of private and non-profit entities with little democratic accountability. Through the language of diversity and inclusivity, 100RC sets in place new networks of capabilities that privilege public-private partnerships in a manner perfectly in keeping with the neoliberalization of global urban governance. The role of the municipal government is not so much diminished as it is refigured though these private-public partnerships and contracts. The private sector is granted increased importance in making cities more resilient by promoting a particular model of global urban resilience: one which frames urban resilience as a marketable commodity that promises to deliver a resilience dividend on one's investment.

However, the connections facilitated by $100 R C$ between cities and Platform Partners are not simply a means of realizing urban resilience. They are the conditions under which a marketplace of ideas, tools and strategies in urban resilience can be created and through which 'resilience value' can be delivered. With the linking of municipal resilience initiatives to the platform partners, 100RC aims to "facilitat[e] a process by which cities help inform and build the market across different sectors for resilience specific services and solutions" (100 Resilient Cities, nd, b). Through 100RC, Platform Partners are afforded privileged access to information pertaining to the resilience needs of numerous municipalities. The idea is to create an information loop within which products and services can then be efficiently tailored in response to the emergent 'resilience challenges' identified by cities, in collaboration with these private consultancies, before they are then marketed worldwide.

The network established through 100RC provides the conditions under which 'resilience value' may be produced. But this is value in the form of profits which accrues directly to private businesses, and which may or may not be tied to broader social or community value as reflected in the idea of the 'resilience dividend'. The creation of a market 
in resilience goods and services clearly represents a 'commodification' of global urban resilience (Leitner et al., 2018: 1281). But it also speaks to transformations in the ways in which governance is organized, knowledge is fostered, and value is created that go beyond the urban resilience ambitions of the Rockefeller Organization and its partners. In the following section, we look to situate the trends we have thus far identified within broader transformations in the ways in which danger, knowledge and value are being recast through the problematic of connectivity.

\section{Governing Connectivity [Subtitle Level 1]}

In the previous sections we have analysed how connectivity figures as a source of new dangers, knowledge and value within the resilience discourse and practices of 100RC. In this section, we will look to situate the approach to resilience governance analysed above within broader contemporary trends in global governance and capitalism associated with neoliberal globalization. The idea is not to identify a causal relation between 100RC and these broader developments, but to more speculatively draw attention to how 100RC is taking advantage of new 'policy corridors' (Wilson, 2013) opened up by the paired evolution of global governance and contemporary capitalism. Instead, the discussion here will centre on three recent developments which help to situate the governmental logic elucidated above with in wider transformations in the structures of global governance and international political economy: 1) the proliferation of multi-scalar governance networks; 2 ) the rise of philanthrocapitalism; and 3) the advent of platform capitalism. These sites demonstrate how the relation between connectivity, knowledge and value is being coupled within governmental initiatives beyond those explicitly related to ideas of resilience. In doing so, this section aims to more explicitly link our analysis of the globalization of resilience ideas above with broader transformations shaping the structures and processes of global governance and international political economy associated with neoliberal globalization.

\section{Multi-Scalar Politics [Subtitle Level 2]}

Over the last 15 years, there has been an extensive conversation within economic and political geography on the simultaneity of neoliberal economic globalization and the rescaling of global 
politics. Commentators argue that the reconfiguration of state spatiality is creating new 'geographies of governance' characterized by the co-presence of multiple, overlapping and often competing authorities within and across different scales of governance. Much of this work on the "new medievalism" (Anderson, 1996) and "glocalization" (Swyngedouw, 2004), has revolved around the rise of 'global cities' as privileged nodes within the circuits of global capital. While these studies have been important in highlighting the growing prominence of cities with global capitalist relations, the tendency has been to focus on the growing competition between such cities (e.g. Swyngedouw \& Baeten, 2001), rather than on how cooperation is also being refigured.

Transnational municipal networks (TMNs) are one example, which is particularly relevant for this study, of how cooperation between global cities is driving innovation in municipal governance. TMNs became a particularly prominent vehicle for addressing issues of global environmental governance initiatives within the European Union (EU) between the mid-1980s and mid-1990s, when they were deployed "as a means of developing both more innovative policy approaches and more rapid policy delivery across large numbers of local authorities" (Bennington \& Harvey, 1999). TMNs have been described as a new "sphere of authority" (Rosenau, 1997) within which "governance is organised in network terms" (Bulkeley, 2005: 877). TMNs operate by side-lining or subverting national governments in order to encourage networks of cities "to establish processes to increase the exchange of information, experience and mutual technical assistance among local authorities" (United Nations, 1992). The networked forms of TMNs can be distinguished from the 'vertical', hierarchical and discrete scales associated with traditional understandings of international regime theory (rationalist or constructivist) in which decisions are understood to be taken at the international level and then 'cascaded' down through the national and subnational arenas of governance (Betsill \& Bulkeley, 2004: 473). By contrast, TMNs locate decisions within and across cities in a way that destabilizes "older hierarchies of scale and conceptions of nested scalings" (Sassen, 2003: 3). Leitner and Sheppard have argued that "by creating space for cooperation among cities, and by operating across the boundaries of territorially based political systems, such networks present participating cities with the opportunity to challenge extant state structures and relations" (2002: 509-510).

The involvement of the Rockefeller Foundation in climate change initiatives was presumably not just a gateway into the world of resilience, but an opportunity to extend 
innovative models of governance to new problem areas. The networked structure of the 100RC imitative clearly mirrors that of TMNs by explicitly aiming to develop a dialogue and exchange of ideas between municipal governments located in different countries in a manner that evades the involvement of national authorities. The network aims to facilitate the transfer of knowledge by allowing cities from around the world to exchange diagnostic information, share best practice and collaborate on strategies designed to address shared areas of concern. However, unlike TMNs, the 100RC initiative opens a generous space for the inclusion of non-governmental actors via the Platform Partners scheme that, as we saw above, prioritizes the development of private-public partnerships and contracts. The foregrounding of the profit-motive as a primary driver for resilience governance undermines the idea that 100RC can be simply understood as a philanthropic initiative. Further insight in this regard can be gleaned by extending this analysis to include recent discussions on the rise of philanthrocapitalism.

\section{Philanthrocapitalism [Subtitle Level 2]}

The term philanthrocapitalism first appeared in a 2006 Economist article, "The Birth of Philanthrocapitalism", and was popularized by Mathew Bishop (an editor at the Economist) and Michael Green's (a former policymaker at the UK's Department for International Development) 2007 book Philanthrocapitalism: How the Rich Can Save the World. ${ }^{2}$ Firstly, philanthrocapitalism refers to the unprecedented scale of philanthropic spending amongst a new class of superrich who made their fortunes primarily in the finance and tech industries (Bishop \& Green, 2006, 2007). It takes place in a context in which we have seen both the scaling back of international development aid budgets by many governments in the Global North and widening rates of economic inequality at the national and international level (Piketty, 2014). The exceptional rate of philanthropic giving must therefore be directly correlated to a global climate of skyrocketing levels of wealth accumulation, increasingly regressive tax policies, and the entrenchment of global economic inequality.

Philanthrocapitalism is, however, characterized by more than simply the size of philanthropic activity. Bishop and Green argue that philanthrocapitalism is a new way of doing philanthropy based on applying "business techniques and ways of thinking to their

\footnotetext{
${ }^{2}$ One year on from its publication and at the height of the financial crisis, a second edition was printed with the less-provocative title Philanthrocapitalism: How Giving Can Save the World.
} 
philanthropy" (Bishop \& Green, 2007: x). Philanthrocapitalism is rooted in the application of business logics and practices in a bid to make philanthropy "strategic," "market conscious," "impact oriented," "knowledge based," and "cost-effective" (Bishop \& Green, 2007: 6). Here we need to be careful. Linsey McGoey $(2012,2014)$, for one, has cast doubt on the novelty of philanthropic organizations taking up the logics and practices of business to make charity more efficient. Both Rockefeller and Carnegie, she notes, were explicit from their charitable ventures' inception as to their desire to apply the rational methods and strategies they developed within their business activities to the ventures' administration (McGoey, 2012: 189). In doing so, they "explicitly ventured to separate their practices from acts of alms giving prevalent within Christian religious orders, which viewed charity as valuable in itself, regardless of whether a donation produced any observable benefits" (McGoey, 2014: 111). In this sense, philanthropy was merely in line with social reformers of the late 19th Century who equally sought to rationalize practices through their dependence on statistics to lead their activities.

Clearly the application of business logics and practices to the realm of philanthropy isn't entirely new. What is particularly novel about the recent resurgence of philanthrocapitalism (beyond its unprecedented scale) is the specific ideas, practices and logics of capital accumulation which are currently being applied from business to philanthropic activities. Just as international businesses have restructured in a period of neoliberal globalization in order to seize the opportunities presented by new forms of capital accumulation, the logics and practices of philanthropy have correspondingly evolved. In this respect, the Rockefeller Foundation's organization of the 100RC initiative not only capitalizes on emergent channels of global governance, but operationalizes a model of management concerned with cultivating network connectivity as a means of 'surfacing' value and knowledge immanently. While this model of management is in a certain sense generalizable, the linking of connectivity, knowledge and value within an emergent mode of production may be clearly discerned within the logics and practices of 'platform capitalism'. In the final section of this analysis we will single out this emergent field of economic production in order to investigate how new models of value creation are being premised on the cultivation and exploitation of network connectivity. Beyond demonstrating how this constellation of connectivity, knowledge and value is rendered profitable within emergent fields of capitalist 
production, this discussion should raise questions regarding the extent to which $100 \mathrm{RC}$ can be strictly viewed as a charitable, non-profit initiative.

\section{Platform Capitalism [Subtitle Level 2]}

Platform capitalism has been described as "a new form of digital economic circulation" (Langley \& Leyshon, 2016: 1) in which value is created by enabling direct interactions between two (or more) distinct types of customers through a digital or multi-sited "platform". In other words, platforms, in one way or another, "seek to facilitate and capture value from the interactions and circulations of Web 2.0" (Langley \& Leyshon, 2016: 6). Examples of this would include a wide variety of new business ventures, from social media platforms such as Facebook to online exchange markets such as Amazon to coordinators of the sharing economy such as Uber. Despite the varied markets these enterprises operate within, and the very different ways they do (or often don't) generate profit, these businesses nevertheless share a distinctive logic and a set of socio-technical practices of value creation rooted in the relationship between intermediation and capitalization (Ash et al., 2018).

Intermediation refers to the matching of lenders with borrowers via an agent or third party, such as a bank, who may obtain a return from their service. Their 'work' involves resolving the coordination problem of matching a buyer with a seller. Platform capitalism refers to the intermediation of digital circulations. Capitalizing on the promise of the internet, platform capitalism has been successful in mobilizing digital tools-namely, the software platform - to overcome this coordination problem at increasing scales. However, the majority of platforms have struggled to turn a profit (Srnicek, 2017). Instead, these enterprises rely on a steady diet of venture capital which they have been able to attract due to historically low global interest rates and the promise that networked effects will translate into conditions of monopolization down the road. The logic of network effects spurs the hope that connectivity can be translated into future profits.

As a charitable vehicle, the Rockefeller Foundation is not directly driven by the profit motive. However, it plays an important intermediary function through the 100RC initiativeeven if the profits for such undertakings are principally absorbed by the Platform Partners. The intermediary function performed by the Rockefeller Foundation might be said to 'condition' how networks come together (Ridgeway, 2015: 287) through its "standardisations, 
inclusions/exclusions, and differentiations" (Langley \& Leyshon, 2016: 9). 100RC operates as an exclusive platform through which municipal governments (customers) are put into contact with specialized agencies and businesses listed as Platform Partners. But the platform does more than simply bringing buyers and sellers together. It exercises governance by promoting constant self-assessment and evaluation by its member cities with respect to their resilience. It cultivates markets by linking these assessments to market-based solutions provided by Platform Partners. It fosters innovation by generating information through these city assessments that can be shared with Platform Partners to inform future product development. And it encourages a spirit of entrepreneurialism where all members are encouraged to buy into the idea that investments in resilience today, will pay dividends in the years to come.

Investments in resilience, we are told, pay dividends not only in times of crisis, but in times of relative normality-as they create competitive advantages for cities, and businesses, in the global marketplace. The promise of a resilience dividend serves to orient the operations of the 100RC initiative. The logic of network effects which explains how connectivity is translated into profits via processes of intermediation within digital platforms, is echoed within the governmental logics of 100RC. Here, governance is directed towards cultivating forms of connectivity that are required to act as a foundation for the generation of resilience value. This raises the question as to whether connectivity can itself be understood as a form of capital-as a condition underpinning new processes of value creation and thus a value-initself. It also raises questions as to who benefits from the generation of this resilience value. Despite the promise of $100 R C$ to deliver value to a wide selection of stakeholders, the way in which 100RC is structured around the Platform Partners suggest that private profit is nonetheless the principal driver for the resilience activities associated with the 100RC initiative.

\section{Conclusion: Connecting Knowledge and Value [Subtitle Level 1]}

The Rockefeller Foundation's 100 Resilient Cities initiative demonstrates one way in which resilience ideas are now being globalized via the structures and processes of global governance affiliated with neoliberal globalization. This article has sought to elucidate the logic of governance enacted within the 100RC initiative. The analysis has focused on how 
connectivity is understood to present novel problems and solutions for achieving urban resilience. We began by analysing how connectivity operates as a governmental problematic and a potential urban resilience solution that is discursively linked to the production of danger, knowledge and value within the resilience discourses of 100RC. We then sought to analyse how this problematic is translated into a programme of governance animating 100RC. Here, we witnessed a form of indirect rule which, rather than directly imposing pre-given resilience solutions, was committed to the cultivation of network connectivity as a condition under which resilience solutions can be immanently surfaced from the interactions of networked stakeholders. In the final section, we connected this governmental logic to broader transformations in the economic and political orders associated with processes of neoliberal globalization. In comparing the processes and structures of 100RC to the contortions of global governmental scale, the intensification of philanthrocapitalism and the emergence of platform capitalism this analysis raised questions concerning how the globalization of resilience ideas is being advanced via the structures and processes set-up by neoliberal globalization.

The imbrication of connectivity, danger, knowledge and value as a constellation animating the governmental logics elucidated here should strike us as curious. I am particularly suspicious of the presumption that solutions to some of the world's most complex problems, in a sense, already exist, albeit in a state of dormancy. The truth is out there; it just needs to be joined-up, actualized, or 'surfaced'. So, the search for global solutions becomes a project of breaking down silos; putting into relation fragmentary perspectives, partial solutions and half-truths; and connecting individuals, groups, and ideas. Solutions exist, but they need to be excavated from the interstices, dusted off and put to work. On the other hand, we should be aware that such an understanding of contemporary security problems facilitates the introduction of novel, technocratic solutions to what many would argue are ultimately political problems.

While this analysis has focused on the specific logic exercised within the 100RC initiative, it is hoped that the analysis undertaken here raises broader questions as to how the problematic of (network) connectivity functions to orient resilience ideas and practices globally. The emergence of connectivity as a governmental problematic should compel us to question how connectivity is understood, valued and evaluated in discrete empirical fields. 
What forms of knowledge are produced through the emphasis on multi/transdisciplinary research and which are being excluded? Who benefits from investments in specific resilience initiatives? What forms of connectivity are regarded as conducive to resilience and which are deemed problematic or even dangerous? Asking such questions may help to broaden resilience beyond the remit of neoliberalism ${ }^{3}$ and help to encourage investments in applications and networks with broader social value.

\section{Note on Contributor (Subtitle Level 1)}

Chris Zebrowski is Director of the Centre for Security Studies (CSS) and Lecturer in Politics and International Relations at Loughborough University, UK. His research has investigated the emergence of resilience discourses and their implications for the rationalities and practices of liberal emergency governance. He is an assistant editor of Resilience: International Policies, Practices and Discourses and author of The Value of Resilience: Securing Life in the TwentyFirst Century (Routledge: 2016).

\section{Correspondence email: C.R.Zebrowski@lboro.ac.uk}

\section{Acknowledgements \& Notes}

This article has benefitted from the comments and critical questions of participants at the 'Localizing Global Security: Technologies, Protocols, Infrastructure' conference at the University of Marburg. I would also like to thank the editors and two anonymous reviewers for provocations and suggestions that have considerably benefitted the ideas presented here. This article was also informed by a presentation given (by the author) and the subsequent discussion with the panellists at the Prague Insecurity Conference in late 2017. The Prague Insecurity Conference was organized by the Ministry of Foreign Affairs of the Czech Republic and the Institute of International Relations Prague, the latter of which is the owner of New Perspectives. The article went through New Perspectives' usual, rigorous and blind peer review process for research articles.

\footnotetext{
${ }^{3}$ A definitive answer as to the extent to which resilience may be reframed outside of, or beyond, dominant neoliberal enframings is beyond the scope of this paper. Some initial thoughts on its possibility can be found in Grove (2019), Anderson (2015) and Zebrowski and Sage (2016).
} 


\section{Bibliography [Subtitle Level 1]}

100 Resilient Cities (nd, a) 'About Us', available at: http://www.100resilientcities.org/about-us\#/- /, accessed 5/09/2019

100 Resilient Cities (nd, b) 'Becoming a Platform Partner', available at: https://100resilientcities.org/becoming-platform-partner/, accessed 5/09/2019

100 Resilient Cities (nd, c) 'City Strategies', available at: https://www.100resilientcities.org/strategies/, accessed 5/09/2019

100 Resilient Cities (nd, d) 'Frequently Asked Questions (FAQ) About 100 Resilient Cities', available at: http://www.100resilientcities.org/pages/100RC-FAQ\#/-, accessed 5/09/2019

100 Resilient Cities (nd, e) 'Selected Cities' available at: http://www.100resilientcities.org/cities/, accessed 5/09/2019

100 Resilient Cities (nd, f) 'What Is the 100 Resilient Cities Platform of Partners?', available at: http://www.100resilientcities.org/what-is-the-100-resilient-cities-platform-of-partners/, accessed 5/09/2019.

100 Resilient Cities (nd, g) 'What Is Urban Resilience?', available at: http://www.100resilientcities.org/resources/, accessed 5/09/2019.

Aldrich, D. P. \& M.A. Meyer (2015), 'Social Capital and Community Resilience', American Behavioral Scientist, 59(2): 254-269.

Anderson, B. (2015), 'What Kind of Thing Is Resilience?', Politics, 35(1): 60-66.

Anderson, J. (1996), 'The Shifting Stage of Politics: New Medieval and Postmodern Territorialities?', Environment and Planning D: Society and Space, 14(2): 133-153.

ARUP (2015), City Resilience Framework. London.

ARUP (2017), City Resilience Index: Understanding and Measuring City Resilience. Available at https://www.arup.com/perspectives/themes/cities/city-resilience-index

Ash, J., B. Anderson, R. Gordon, \& P. Langley (2018), 'Unit, Vibration, Tone: A Post-phenomenological Method for Researching Digital Interfaces', Cultural Geographies, 25(1): 165-181.

Betsill, M. M. \& H. Bulkeley (2004), 'Transnational Networks and Global Environmental Governance: The Cities for Climate Protection Program', International Studies Quarterly, 48(2): 471-493.

Bishop, M. \& M. Green (2006), 'The Birth of Philanthrocapitalism', The Economist, 02/02/2006: 9-12.

Bishop, M. \& M. Green (2007), Philanthrocapitalism: How the Rich Can Save the World, New York: Bloomsbury.

Bulkeley, H. (2005), 'Reconfiguring Environmental Governance: Towards a Politics of Scales and Networks', Political Geography, 24(8): 875-902.

Chandler, D. (2014), Resilience: The Governance of Complexity, London: Routledge.

Collier, S. J., S. Cox, \& K.J. Grove (2016), 'Rebuilding by Design in Post-Sandy New York', LIMN, (7), no pagination. Available at https://limn.it/articles/rebuilding-by-design-in-post-sandy-new-york/

Evans, B. \& J. Reid (2014), Resilient Life: The Art of Living Dangerously, Cambridge: Polity Press.

Gilpin, D. R. \& P. J. Murphy (2008), Crisis Management in a Complex World, Oxford: Oxford University Press.

Goldstein, B. E., A. B. Liel, A. Javernick-Will, R. Soden, E. Arneson, L. Palen, C. Chase, D. Deniz, L. Sprain, \& S. Dashti (2015), 'The Polyvocality of Resilience: Discovering a Research Agenda 
through Interdisciplinary Investigation and Community Engagement', in Proceedings of the ISCRAM 2015 Conference, pp. 225-234. Kristiansand.

Grove, K. (2019), Resilience, London: Routledge.

Hadfield, S. \& G. Hassob (2009), Bounce: Use the Power of Resilience to Live the Life You Want, Harlow: Pearson Education Ltd.

Holling, C. S. (2001), 'Understanding the Complexity of Economic, Ecological, and Social Systems', Ecosystems, 4(5): 390-405.

Joseph, J. (2013), 'Resilience in UK and French Security Strategy: An Anglo-Saxon Bias?', Politics, 33(4): 253-264.

Joseph, J. (2016), 'Governing through Failure and Denial: The New Resilience Agenda', Millennium Journal of International Studies, 44(3): 1-21.

Klein, N. (2007), The Shock Doctrine: The Rise of Disaster Capitalism, New York: Metropolitan Books.

Langley, P. \& A. Leyshon (2016), 'Platform Capitalism: The Intermediation and Capitalisation of Digital Economic Circulation', Finance and Society, 3(1): 11-31.

Leitner, H. \& E. Sheppard (2002), '“The City Is Dead, Long Live the Net": Harnessing European Interurban Networks for a Neoliberal Agenda', Antipode, 34(3): 495-518.

Leitner, H., E. Sheppard, S. Webber, \& E. Colven (2018), 'Globalizing Urban Resilience', Urban Geography, 39(8): 1276-1284.

Lentzos, F. \& N. Rose (2009), 'Governing Insecurity: Contingency Planning, Protection, Resilience', Economy and Society, 38(2): 230-254.

Lewis, T. G. (2009), Network Science: Theory and Practice, Hoboken, NJ: John Wiley \& Sons.

Luthans, F., K. W. Luthans, \& B. C. Luthans (2004), 'Positive Psychological Capital: Beyond Human and Social Capital', Business Horizons, 47(1): 45-50.

Luthans, F., G. R. Vogelgesang, \& P. B. Lester (2006), 'Developing the Psychological Capital of Resiliency', Human Resource Development Review, 5(1): 25-44.

McGoey, L. (2012), 'Philanthrocapitalism and Its Critics', Poetics, 40(2): 185-199.

McGoey, L. (2014), 'The Philanthropic State: Market-State Hybrids in the Philanthrocapitalist Turn', Third World Quarterly, 35(1): 109-125.

Miller, P. \& N. Rose (1992), 'Political Power beyond the State: Problematics of Government', The British Journal for Sociology, 43(2): 173-205.

Mulligan, M. \& P. Rogers (2017), 'Looking at Emergent and Multi-scale Governance through the Lens of Community Formation', Resilience: International Policies, Practices and Discourses, 6(3): 145162.

Neocleous, M. (2013), 'Resisting Resilience', Radical Philosophy, 178: 2-7.

Oaklander, M. (2015), 'Bounce: Scientists Now Know Why Some People Rebound So Well from Setbacks', Time Magazine, 185(20): 38-42.

Piketty, T. (2014), Capital in the Twenty-First Century, Cambridge: The Belknap Press of Harvard University Press.

Rademaker, M., K. Jans, P. Verhagen, A. Boeschoten, H. Rõõs, \& S. Slingerland (2018), Making Cities in Conflict Areas More Resilient, A Conceptual Iteration: Using the Climate Resilience and Security Monitor for Policies in Practice, Hague.

Reid, J. (2012), 'The Disastrous and Politically Debased Subject of Resilience', Development Dialogue, 58: 67-80. 
Ridgeway, R. (2015), 'Crowdfunding the Commons?', in G. Lovink, N. Tkacz, \& P. de Vries (eds.) Moneylab Reader: An Intervention in Digital Economy, Amsterdam: Institute of Network Cultures, pp. 281-294.

Rockefeller Foundation (nd) 'Homepage', available at: https://www.rockefellerfoundation.org/, accessed 5/09/2019.

Rockefeller Foundation (2009), Building Climate Change Resilience, New York. Available at https://www.acccrn.net/resources/rockefeller-foundation-white-paper-building-climatechange-resilience

Rodin, J. (2014), The Resilience Dividend: Being Strong in a World Where Things Go Wrong, New York: Public Affairs.

Rogers, P. (2019), 'The Resilient City: Where Do We Go From Here?', in J. Bohland, S. Davoudi \& J. L. Lawrence (eds.) The Resilience Machine, New York: Routledge, pp. 125-143.

Rosenau, J. N. (1997), Along the Domestic-Foreign Frontier: Exploring Governance in a Turbulent World. Cambridge Studies in International Relations (Vol. 53), Cambridge: Cambridge University Press.

Sassen, S. (2003), 'Globalization or Denationalization?', Review of International Political Economy, 10(1): 1-22.

Srnicek, N. (2017), Platform Capitalism, Cambridge: Polity Press.

Swyngedouw, E. (2004), 'Globalisation or "Glocalisation"? Networks, Territories and Re-Scaling', Cambridge Review of International Affairs, 17(1): 1-46.

Swyngedouw, E. \& G. Baeten (2001), 'Scaling the City: The Political Economy of 'Glocal' Development - Brussels' Conundrum', European Planning Studies, 9(7): 827-849.

Taleb, N. N. (2012), Antifragile: Things That Gain from Disorder, New York: Random House.

Tierney, K. (2015), 'Resilience and the Neoliberal Project: Discourses, Critiques, Practices-and Katrina', American Behavioral Scientist, 59(10): 1327-1342.

United Nations (1992), Agenda 21, Nairobi: UNEP.

Wagner, D. \& D. Disparte (2016), Global Risk Agility and Decision Making: Organizational Resilience in the Era of Man-Made Risk, London: Palgrave Macmillan.

Walker, J. \& M. Cooper (2011), 'Genealogies of Resilience: From Systems Ecology to the Political Economy of Crisis Adaptation', Security Dialogue, 14(2): 143-160.

Wilson, G. A. (2013), 'Community Resilience, Policy Corridors and the Policy Challenge', Land Use Policy, 31: 298-310.

Wilson, S., L. J. Pearson, Y. Kashima, D. Lusher, \& C. Pearson (2013), 'Separating Adaptive Maintenance (Resilience) and Transformative Capacity of Social-Ecological Systems', Ecology and Society, 18(1).

Youssef, C. M. \& F. Luthans (2007), 'Positive Organizational Behavior in the Workplace: The Impact of Hope, Optimism, and Resilience', Journal of Management, 33(5): 774-800.

Zebrowski, C. (2013), 'The Nature of Resilience', Resilience: International Policies, Practices and Discourses, 1(3): 159-173.

Zebrowski, C. (2016), The Value of Resilience: Securing Life in the 21st Century, London: Routledge.

Zebrowski, C. \& D. Sage (2016), 'Organizing Community Resilience: An Examination of the Forms of Sociality Promoted in Community Resilience Programmes', Resilience: International Policies, Practices and Discourses, 5(1): 44-60. 
